\title{
Ilhas de vegetação em afloramentos de quartzito-arenito no Morro do Pai Inácio, Chapada Diamantina, Bahia, Brasil ${ }^{1}$
}

\author{
Abel Augusto Conceição $0^{2,4}$, Ana Maria Giulietti² e Sérgio Tadeu Meirelles ${ }^{3}$
}

\author{
Recebido em 31/03/2006. Aceito em 20/10/2006
}

\begin{abstract}
RESUMO - (Ilhas de vegetação em afloramentos de quartzito-arenito no Morro do Pai Inácio, Chapada Diamantina, Bahia, Brasil). Ilhas de vegetação rodeadas de superfície rochosa foram estudadas em dois platôs do Morro do Pai Inácio ( $41^{\circ} 28^{\prime} \mathrm{W}$ e $\left.12^{\circ} 27^{\prime} \mathrm{S}\right)$, na Chapada Diamantina. Tais platôs possuem afloramentos de quartzito-arenito entremeados por solos arenosos e ácidos, situados nas porções mais elevadas do Morro, entre 1.100 e 1.170 m acima do nível do mar, sob clima com estação seca bem definida. As ilhas foram assumidas como agrupamentos de uma ou mais espécies de plantas vasculares limitados pela superfície rochosa sem plantas vasculares em toda borda. O estudo incluiu 39 ilhas de vegetação de diferentes tamanhos em cada platô, onde predominaram ervas e arbustos de 63 espécies, sendo 22 comuns a ambos os platôs. Espécies de Liliopsida foram mais numerosas, freqüentes e dominantes, com predomínio das famílias Velloziaceae, Cyperaceae, Orchidaceae, Bromeliaceae e Guttiferae nas ilhas de vegetação em ambos os platôs, assim como a forma de vida caméfita. Foram constatadas riquezas similares nas ilhas de ambos os platôs, sendo a maioria delas formada por até cinco espécies. O agrupamento das espécies utilizando UPGMA e o índice de similaridade de Jaccard revelou quatro grupos, dois deles constituídos por espécies características das ilhas mais expostas ao sol, enquanto outro é constituído por espécies mais relacionadas aos locais mais sombreados e um quarto relacionado a espécies mais generalistas. A associação entre Vellozia hemisphaerica Seub. e Trilepis lhotzkiana Nees mostrou-se típica dos afloramentos do Morro do Pai Inácio. Apenas as famílias Orchidaceae e Cyperaceae estiveram presentes nas duas menores classes de tamanho insular, enquanto Guttiferae, Rubiaceae e Bromeliaceae tiveram maior proporção de ocorrência na maior classe. Diferenças na composição e abundância de espécies entre os platôs sugerem a existência de diferenças ambientais e isolamentos, interferindo na distribuição espacial das espécies nas ilhas de vegetação em cada platô.
\end{abstract}

Palavras-chave: campo rupestre, fitossociologia, afloramento rochoso, inselberg, ilha de vegetação

ABSTRACT - (Islands of vegetation on quartzite-sandstone outcrops, Pai Inácio Mountain, Chapada Diamantina, Bahia, Brazil). Islands of vegetation on rocky surfaces were studied on two plateaus at Pai Inácio Mountain $\left(41^{\circ} 28^{\prime} ; 12^{\circ} 27^{\prime} \mathrm{S}\right)$ in the Chapada Diamantina. Both plateaus have quartzite-sandstone outcrops interspersed with sandy, acidic soils at the summit between 1,100 and 1,170 meters above sea level, with a well-defined dry season. Islands are defined as clumps of one or more species of vascular plants completely surrounded by a rocky surface devoid of vascular plants. The study included 39 vegetation islands of different sizes on each plateau, with 63 herb and shrub species, of which 22 are common to both plateaus. Liliopsida species had the highest abundance, frequency and dominance, with Velloziaceae, Cyperaceae, Orchidaceae, Bromeliaceae, and Guttiferae families predominating on both plateaus. The chamaephyte life-form was also predominant. Similar species richness was detected on both plateaus, with most of the islands composed of up to five species. Four species groups were revealed using UPGMA and Jaccard's similarity index, two groups with species typical of sunlit islands, one group with species from shadier sites, and a fourth composed of more generalist species. The Vellozia hemisphaerica - Trilepis lhotzkiana association was typical of rocky outcrops at Pai Inácio Mountain. Orchidaceae and Cyperaceae were the only families present in the two smallest island-size classes, while Guttiferae, Rubiaceae and Bromeliaceae were mostly present in the largest class. Variation in species composition and abundance between the two plateaus suggest environmental and isolation differences affecting the species spatial distribution in the vegetation islands on each plateau.

Key words: campo rupestre, phytosociology, rocky outcrop, inselberg, vegetation island

\section{Introdução}

As ilhas oceânicas foram e são objetos de muitos estudos ecológicos, já que são mais simples do que continentes ou oceanos, são visivelmente distinguíveis, além de haver maior possibilidade de identificar e contar seus indivíduos. Pela sua multiplicidade e variação de formas, tamanhos, graus de isolamento e ecologia, as ilhas disponibilizam replicações naturais de experimentos, necessárias aos testes de hipóteses

1 Parte da Dissertação de mestrado do primeiro Autor

2 Universidade Estadual de Feira de Santana, Departamento de Ciências Biológicas (DCBIO), BR 116 N km 03, Campus Universitário, 44031-460 Feira de Santana, BA, Brasil

3 Universidade de São Paulo, Instituto de Biociências, Departamento de Ecologia, C. Postal 11461, Cidade Universitária, 05422-970 São Paulo, SP, Brasil

4 Autor para correspondência: abel18@gmail.com 
evolutivas, facilitando a compreensão de processos envolvidos na dispersão, invasão, competição, adaptação e extinção (MacArthur \& Wilson 1967). De modo análogo às ilhas oceânicas, tais processos também podem ser investigados em sistemas insulares terrestres, como aqueles encontrados em montanhas, ou ainda, em uma escala bem mais restrita, nos agregados de vegetação separados por um "oceano" de rocha exposta (McCormick et al. 1974; Wiser et al. 1996).

Ilhas de plantas agrupadas em áreas pequenas e bem delimitadas pelo substrato rochoso de granitognaisse foram bastante estudadas na África e nos Estados Unidos, envolvendo enfoques variados em ecologia, como descrição estrutural e aspectos funcionais e temporais relacionados à sucessão primária (Weaver \& Clements 1938; Burbanck \& Platt 1964; Hambler 1964; McCormick et al. 1974; Shure \& Ragsdale 1977; Porembski et al. 1995). Mesmo situadas em regiões distintas, essas ilhas de vegetação sobre rocha apresentam similaridades fisionômicas, apesar da distinção regional na composição de espécies de plantas (Porembski et al. 1994; Seine et al. 2000). Bromeliaceae, Cactaceae, Cyperaceae, Orchidaceae, Poaceae e Velloziaceae são algumas das famílias mais marcantes em ilhas de vegetação sobre afloramentos rochosos da região neotropical (Ibisch et al. 1995), onde foram descritas novas associações entre espécies (Sarthou \& Villiers 1998) e verificado aumento progressivo no número de espécies lenhosas, na medida em que a área da ilha de vegetação aumentava (Michelangeli 2000).

No Brasil, os poucos trabalhos com enfoque na vegetação agregada e delimitada pela superfície rochosa são concentrados nos afloramentos de granitognaisse, no Rio de Janeiro (Meirelles 1990; Meirelles et al. 1999; Ribeiro \& Medina 2002), em São Paulo (S.T. Meirelles, dados não publicados) e no Rio Grande do Sul (C.C. Waldemar, dados não publicados). Quando essa vegetação insular ocorre em topos de morros, ocasiona uma situação de dupla insularidade, na qual a vegetação se agrega em ilhas na rocha descontínua (localmente insular), restritas às áreas mais altas das serras e morros isolados no relevo (regionalmente insular).

A região montanhosa da Chapada Diamantina, na Bahia, destaca-se pelo elevado grau de endemismo, indicando sua grande importância biológica (Giulietti \& Pirani 1988; Prance 1994; Giulietti et al. 1997). Tal constatação estimulou o estudo ecológico da vegetação de seus afloramentos rochosos, indicando a grande contribuição dos afloramentos isolados para o aumento da diversidade regional (Conceição \& Pirani 2005; Conceição et al. 2005). O Morro do Pai Inácio, na Chapada Diamantina, foi estudado quanto à composição florística e aspectos estruturais (Conceição \& Giulietti 2002), sendo verificada grande complexidade da vegetação, sugerindo-se que o elevado número de espécies encontrado (144) tenha forte relação com a combinação de diferentes tipos de habitats em área restrita. De fato, as porções mais elevadas do Morro do Pai Inácio incluem-se no complexo vegetacional do campo rupestre, rico em diferentes habitats conforme características do substrato e continuidade da vegetação (Conceição 2000; Conceição \& Pirani 2005), sendo freqüente ao longo da Cadeia do Espinhaço, dominando a paisagem nas regiões geralmente acima de $1.000 \mathrm{~m}$ de altitude (Giulietti \& Pirani 1988; Harley 1995; Giulietti et al. 1997). Campos extensos dominam as partes relativamente planas das porções elevadas das serras, enquanto a vegetação de afloramentos rochosos é freqüentemente encontrada nas rochas expostas dos topos, circundada pela vegetação com predomínio de gramíneas e arbustos (Conceição \& Pirani 2005).

O presente trabalho tem como objetivo caracterizar a composição florística e detectar associações de espécies em ilhas de vegetação dos afloramentos rochosos do Morro do Pai Inácio e verificar o efeito do tamanho insular na diversidade florística das ilhas.

\section{Material e métodos}

O Morro do Pai Inácio $\left(12^{\circ} 27^{\prime} \mathrm{S}\right.$ e $\left.41^{\circ} 28^{\prime} \mathrm{W}\right)$ situa-se no município de Palmeiras, dentro da Área de Proteção Ambiental Marimbus-Iraquara, vizinha ao Parque Nacional da Chapada Diamantina, Bahia, Brasil. Em relação à geologia, o Morro é uma elevação do Supergrupo Espinhaço, Grupo Chapada Diamantina, Formação Tombador, com predomínio de arenitos intercalados com siltitos nos topos, e conglomerados formados por fragmentos de quartzito e rochas graníticas variáveis em tamanhos (Torquato \& Fogaça 1981; Misi \& Silva 1996). O Morro possui dois platôs próximos (Fig. 1), focos do presente estudo realizado de janeiro a abril de 1997. O mais alto possui cerca de 2 ha de superfície, incluindo o cume a $1170 \mathrm{~m}$ de altitude, sendo aqui designado como Platô Cruz, enquanto o outro platô, com cerca de 1,3 ha, localiza-se cerca de $50 \mathrm{~m}$ abaixo, sendo denominado aqui como Platô Dois. Apesar de próximos, os platôs estão sujeitos a diferentes condições ambientais. O Platô Cruz é mais 


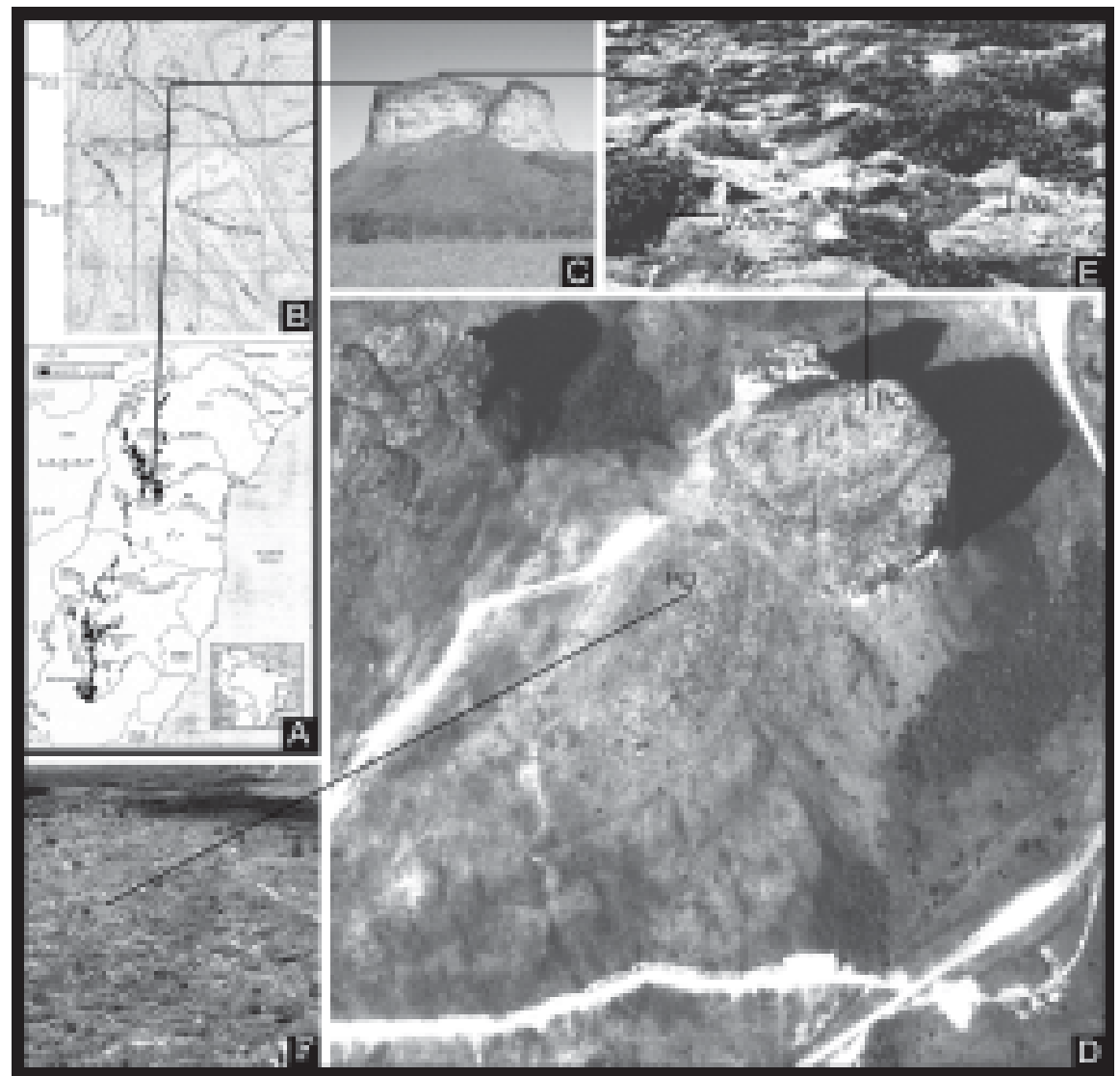

Figura 1. Morro do Pai Inácio, Chapada Diamantina, Bahia, Brasil. A. Mapa ressaltando as áreas acima de $1.000 \mathrm{~m}$ de altitude na Cadeia do Espinhaço, com linha partindo da Serra do Sincorá (adaptado de Giulietti et al. 1997). B. Localização no mapa topográfico 1:100.000 (SUDENE). C. Morro isolado na paisagem. D. Fotografia aérea do topo do Morro do Pai Inácio, mostrando o Platô Cruz (PC) e o Platô Dois (PD). E. Platô Cruz, com ilhas de vegetação compostas principalmente por Vellozia hemisphaerica Seub. (V.hem.) e Trilepis lhotzkiana Nees (T.lho.). F. Platô Dois visto da encosta do Platô Cruz.

inclinado, possui maior extensão de rocha exposta e maior incidência de fortes ventos e insolação, sendo que o Platô Dois é mais próximo ao cerrado circundante (Conceição \& Giulietti 2002). A região onde se localiza a área de trabalho está sob influência de clima do tipo Tropical do Brasil Central, subquente, semi-úmido, com verão úmido e quatro a cinco meses secos, concentrados na primavera (Nimer 1989).

Definiu-se como ilha de vegetação aqueles agrupamentos de plantas formados por uma ou mais espécies vasculares fixadas diretamente sobre a rocha ou em solo raso, delimitados pela superfície rochosa. Tal definição difere da empregada por Conceição \& Pirani (2005), que consideram as ilhas como agregados de duas ou mais espécies, tendo sido denominados de "ilhas de solo". Na África, tal vegetação foi designada como "soil mats communities" (Hambler 1964) e nos Estados Unidos como "island communities" (Burbanck \& Platt 1964; McCormick et al. 1974; Shure \&
Ragsdale 1977).

Foram estudadas 78 ilhas de vegetação, sendo 39 em cada platô. Devido ao elevado número de ilhas ocorrentes nos platôs, sortearam-se unidades distribuídas no centro e nas bordas dos platôs, onde havia extensas áreas de rocha exposta. Apesar das ilhas amostradas constituírem-se homogêneas devido ao isolamento pela rocha exposta, elas possuem algumas variações de microhabitats, com algumas ilhas presentes em locais bastante expostos à incidência luminosa ou nas proximidades de encostas mais sombreadas, ou ainda em locais sob maior influencia dos canais de drenagem, onde há acumulo de água por período de tempo mais longo. Nenhuma ilha inclui "mini-cavernas", como aquelas estudadas nos campos rupestres em Minas Gerais (Alves \& Kolbek 1993), bastante sombreadas e protegidas sob porções de rocha. Cada unidade insular foi analisada quanto à área, espécies ocorrentes e respectivas coberturas. Para 
estimativa das áreas insulares, as unidades foram mapeadas e representadas de maneira proporcional em papel milimetrado. Cada molde foi pesado e seu peso relacionado ao padrão de área conhecida, revelando as áreas estimadas.

Para detectar padrões de ocupação das ilhas conforme o gradiente de área das ilhas, sete classes de tamanho foram estabelecidas por intervalos regulares do logaritmo da área na base 10, nas quais foram analisadas as ocorrências das espécies com dominância absoluta maior do que cinco. O número de ocorrências em cada classe de tamanho foi dividido pelo total de ocorrências da espécie nas sete classes, expresso em porcentagem nos gráficos elaborados para cada uma das 10 espécies analisadas.

Os testemunhos correspondentes às espécies de plantas vasculares encontradas nas ilhas de vegetação foram incluídos no herbário SPF (Instituto de Biociências, Universidade de São Paulo). Os táxons em nível de família, classe e divisão seguiram Cronquist (1981) e o nome dos autores das espécies segundo Brummitt \& Powell (1992). As formas de vida de Raunkiaer revisadas (Mueller-Dombois \& Ellenberg 1974) foram determinadas e representadas graficamente em espectros biológicos, acrescentando-se a forma suculenta como classe à parte (Conceição \& Pirani 2005).

Os parâmetros fitossociológicos utilizados para a caracterização da estrutura das ilhas de vegetação foram frequiência e dominância das espécies, absoluta e relativa (Mueller-Dombois \& Ellenberg 1974). Os valores de dominância foram obtidos do grau de cobertura (Magurran 1988), estimado pela proporção da área insular ocupada pela espécie (Westhoff \& Maarel 1978). Os valores de dominância foram separados em cinco classes de cobertura proporcionais às áreas de cada ilha: até 1,5\%, 1,51-5\%, 5,01-25\%, $25,01-50 \%$ e maior que $50 \%$. A riqueza específica $(S)$, a diversidade específica $\left(H^{\prime}\right)$ de Shannon-Wiener na base neperiana e a equitabilidade ( $\left.J^{\prime}\right)$ de Pielou foram os parâmetros da comunidade considerados (Krebs 1989). O cálculo de $H^{\prime}$ considerou os valores de dominância relativa como valores de abundância $\left(p_{\mathrm{i}}\right)$.

A estrutura e as associações na comunidade foram evidenciadas pelo dendrograma de similaridade elaborado a partir da matriz binária de espécies ocorrentes em cinco ou mais ilhas de vegetação (Pielou 1984), empregando-se o índice de similaridade de Jaccard (Mueller-Dombois \& Ellenberg 1974) e UPGMA. Todos os cálculos foram feitos com o programa FITOPAC 1.6. (Shepherd 2006).

\section{Resultados}

As áreas das ilhas variaram de $0,003 \mathrm{~m}^{2}$ a $7,296 \mathrm{~m}^{2}$. Aárea total nas ilhas analisadas foi de $74,8 \mathrm{~m}^{2}$ nos dois platôs, sendo $33,8 \mathrm{~m}^{2}$ no Platô Dois e 41,0 m² no Platô Cruz. O número de ilhas por classe de tamanho insular variou de duas a 22. A maioria das ilhas apresentou área intermediária, sendo as menores classes de tamanho constituídas por um pequeno número de ilhas (Fig. 2). O intervalo de área determinado pelo logaritmo foi de 0,48 .

Foram encontradas 63 espécies de plantas vasculares nas ilhas de vegetação dos dois platôs, sendo 43 no Platô Dois e 42 no Platô Cruz (Tab. 1). As famílias com maior número de espécies foram Orchidaceae (11), Bromeliaceae (10), Poaceae (5), Apocynaceae (4), Cyperaceae (4) e Velloziaceae (4). As espécies encontradas apenas em um dos platôs totalizaram 41 (65\%), sendo 21 espécies exclusivas do Platô Dois e 20 exclusivas do Platô Cruz. As famílias ocorrentes em mais de $20 \%$ das ilhas de vegetação foram as mesmas em ambos os platôs, sendo elas: Cyperaceae, Orchidaceae, Velloziaceae, Bromeliaceae e Guttiferae. Foram observados valores baixos de riqueza por ilha, sendo que $75 \%$ das ilhas apresentaram entre uma a cinco espécies. Das 15 ilhas com apenas uma espécie, Trilepis lhotzkiana ocorreu em sete, Cattleya elongata em quatro, Acianthera ochreata em duas e Vellozia hemisphaerica e Octomeria alexandrii, em uma. As ilhas com uma única espécie corresponderam às menores ilhas, sendo que dessas ilhas, as maiores incluíram T. lhotzkiana ou V. hemisphaerica. As demais ilhas de tamanho pequeno foram compostas principalmente por combinações dessas espécies encontradas isoladamente na rocha, acrescentando-se

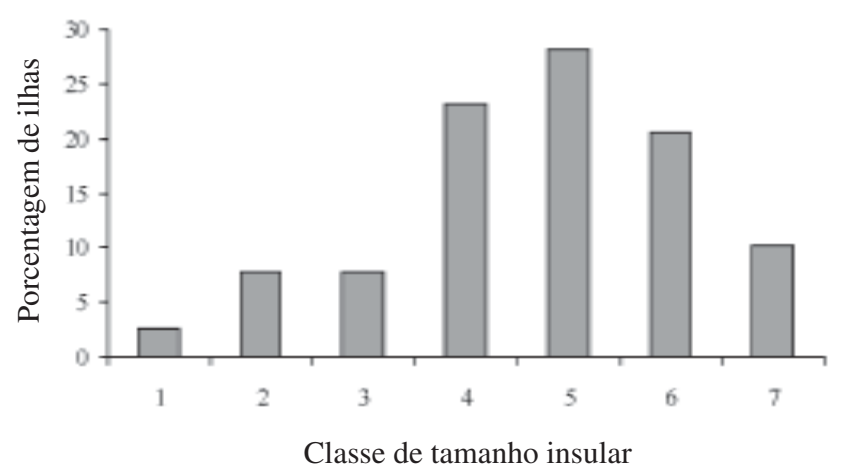

Figura 2. Porcentagem de ilhas por classes de tamanho no Morro do Pai Inácio, Chapada Diamantina, Bahia, Brasil. 


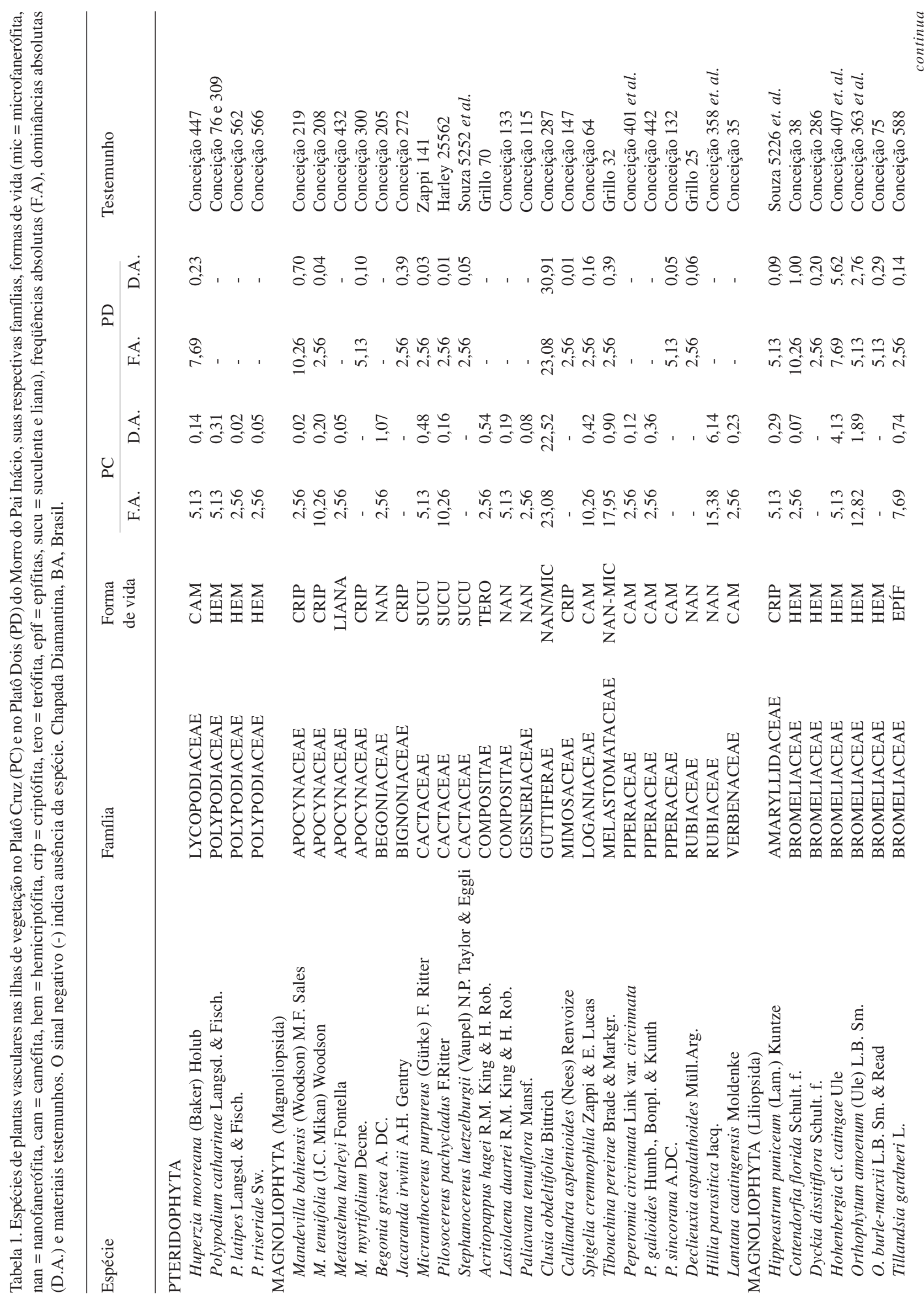




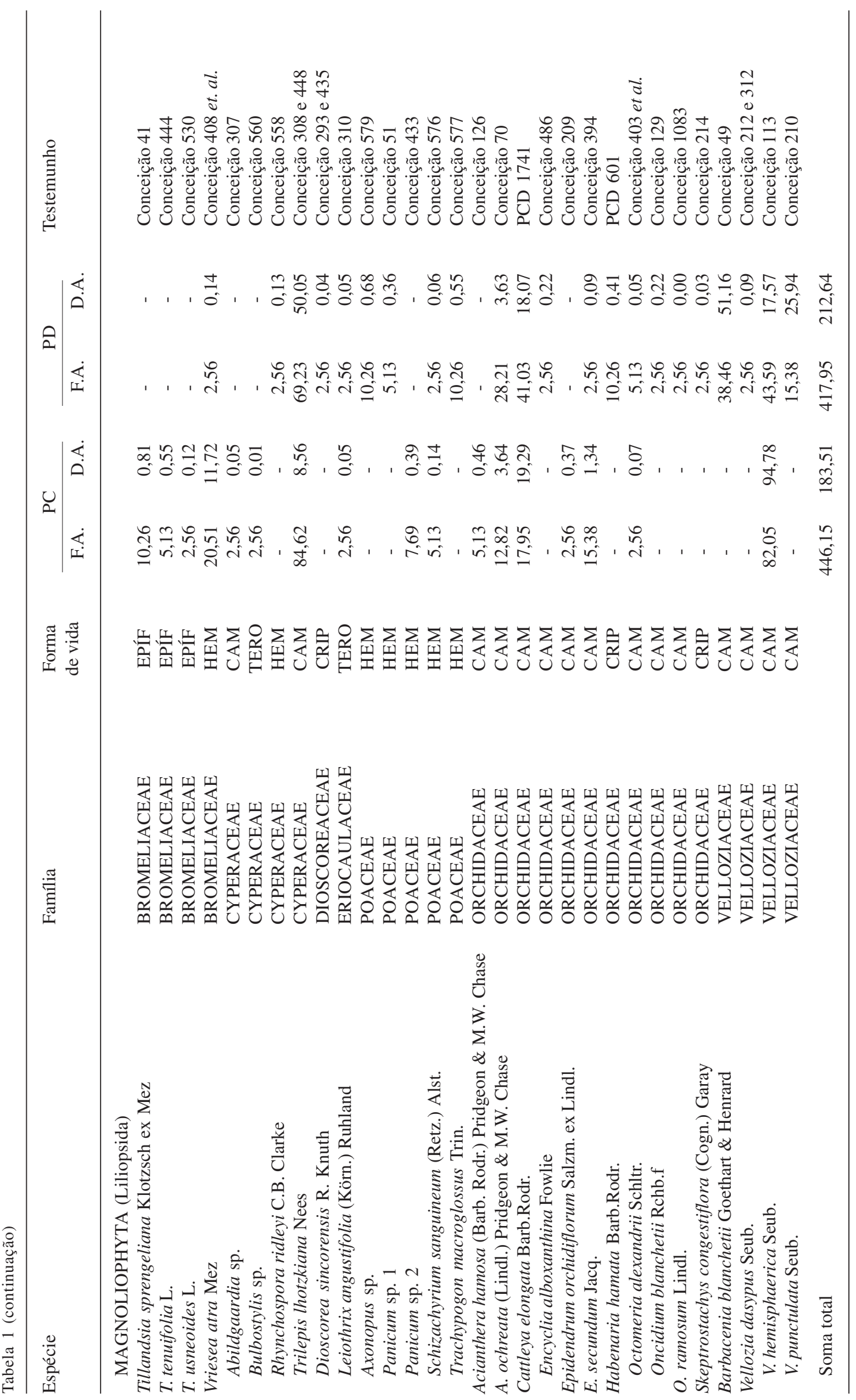


Barbacenia blanchetii. O maior número de espécies em uma ilha foi 20. Os valores dos índices de Shannon (nats) foram 1,83 no Platô Cruz; 2,07 no Platô Dois e 2,71 no conjunto de unidades insulares. A equitabilidade $(J ')$ total foi de 0,54 , sendo os valores 0,49 para o Platô Cruz e 0,55 para o Platô Dois.

A forma de vida predominante foi caméfita, seguida por hemicriptófita (Fig. 3 e Tab. 1). A proporção de formas de vida foi relativamente similar nos dois platôs, sendo observada tendência a maior proporção de criptófita no platô Dois, e de fanerófita, terófita e epífita no Platô Cruz. Liana foi amostrada exclusivamente no Platô Cruz.

Considerando os dois platôs em conjunto, as espécies com frequiência absoluta maior do que $20 \%$ foram $T$. lhotzkiana $(76,9 \%), V$. hemisphaerica (62,8\%), C. elongata (29,5\%), Clusia obdeltifolia (23,1\%) e A. ochreata (20,5\%) (Tab. 1). Em relação à dominância absoluta para os platôs em conjunto, as espécies com mais de $20 \%$ foram $V$. hemisphaerica (56,2\%), T. lhotzkiana (29,3\%), C. obdeltifolia $(26,7 \%)$ e B. blanchetii (25,6\%) (Tab. 1). As espécies de Velloziaceae B. blanchetii e Vellozia punctulata foram ausentes no Platô Cruz e bem representadas no Platô Dois, ao contrário de Hillia parasitica, uma Rubiaceae bem representada no Platô Cruz e ausente da amostra no Platô Dois.

O dendrograma de similaridade possuindo correlação cofenética de 0,85 distingue quatro grupos com similaridade a partir de $25 \%$ e a Orchidaceae A. ochreata isolada (Fig. 4). A associação mais evidente é entre $V$. hemisphaerica e T. lhotzkiana, com $80 \%$ de similaridade. Os grupos são formados

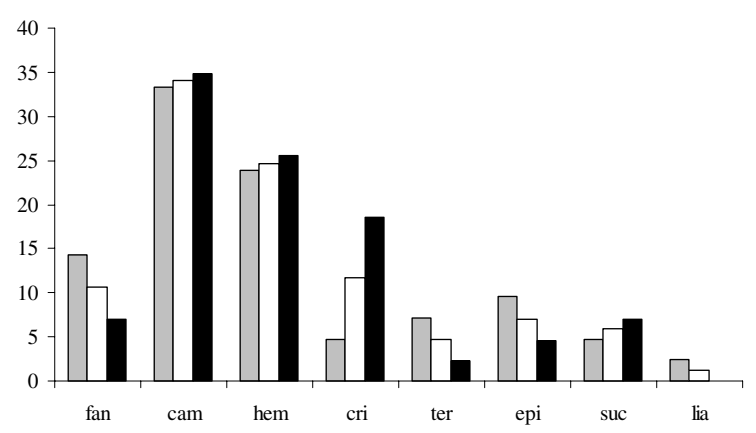

Figura 3. Porcentagem de espécies segundo as formas de vida (fan: fanerófita, cam: caméfita, hem: hemicriptófita, cri: criptófita, ter: terófita, epi: epífita, suc: suculenta, lia: liana) presentes nas ilhas de vegetação dos platôs Cruz (PC) e Dois (PD) isoladamente e em conjunto, no Morro do Pai Inácio, Chapada Diamantina, Bahia, Brasil. ( $\square=$ Ilhas PC; $\square=$ Ilhas PD + PC; $\square=$ Ilhas PD). por espécies de Cyperaceae, Velloziaceae e Guttiferae; Orchidaceae e Velloziaceae; Orchidaceae e Melastomataceae e por Bromeliaceae e Rubiaceae. A similaridade florística de Jaccard entre os dois platôs é 0,35 .

A ocupação das ilhas conforme suas classes de tamanho mostrou tendência no aumento da proporção de ilhas ocupadas até as classes intermediárias, decrescendo posteriormente, com exceção de espécies das famílias Guttiferae, Bromeliaceae e Rubiaceae, que tenderam a ocorrer em maior proporção nas maiores classes de tamanho (Fig. 5). Apenas espécies de Orchidaceae e Cyperaceae ocorreram nas duas menores classes de tamanho.

\section{Discussão}

Muitas espécies levantadas neste estudo também ocorrem em outros afloramentos rochosos na Chapada Diamantina, sendo que parte dessas, são endêmicas da região (Conceição et al. 2005). Das seis espécies que apresentaram dominância absoluta maior do que 15 em pelo menos um dos platôs, cinco são endêmicas da Chapada Diamantina (B. blanchetii, C. elongata, C. obdeltifolia, V. hemisphaerica e V. punctulata), demonstrando a forte influência dessas espécies para fisionomia e estrutura das ilhas. Apesar disso, outras espécies ocorrem além da Chapada Diamantina, como Epidendrum secundum, $H$. parasitica, Hippeastrum puniceum, Mandevilla tenuifolia, Oncidium blanchetii, Peperomia galioides, Polypodium catharinae, P. triseriale, T. lhotzkiana e V. atra. Ao considerar gêneros e famílias, quase todos os táxons são representados em outros locais, sendo que todas as famílias ocorrem em pelo menos mais um local além da Chapada Diamantina (Oliveira et al. 1975; Carauta \& Oliveira 1984; Ibisch et al. 1995; S.T. Meirelles, dados não publicados; França et al. 1997; Porembski et al. 1998; Sarthou \& Villiers 1998; C.C. Waldemar, dados não publicados; Meirelles et al. 1999; Alves \& Kolbek 2000; Michelangeli 2000; Safford \& Martinelli 2000; Ribeiro \& Medina 2002; Caiafa \& Silva 2005). O elevado número de espécies endêmicas relacionadas aos afloramentos rochosos em morros pode ter relação com o isolamento desses locais (Giulietti \& Pirani 1988; Ibisch et al. 1995; Safford \& Martinelli 2000), enquanto que a elevada proporção de gêneros e famílias comuns provavelmente se deve ao ambiente típico e severo (Burrows 1990), que restringe a ocupação aos vegetais com características especiais, limitadas a uma determinada gama de táxons. 
342 Conceição, Giulietti \& Meirelles: Ilhas de vegetação em afloramentos de quartzito-arenito no Morro do Pai Inácio...

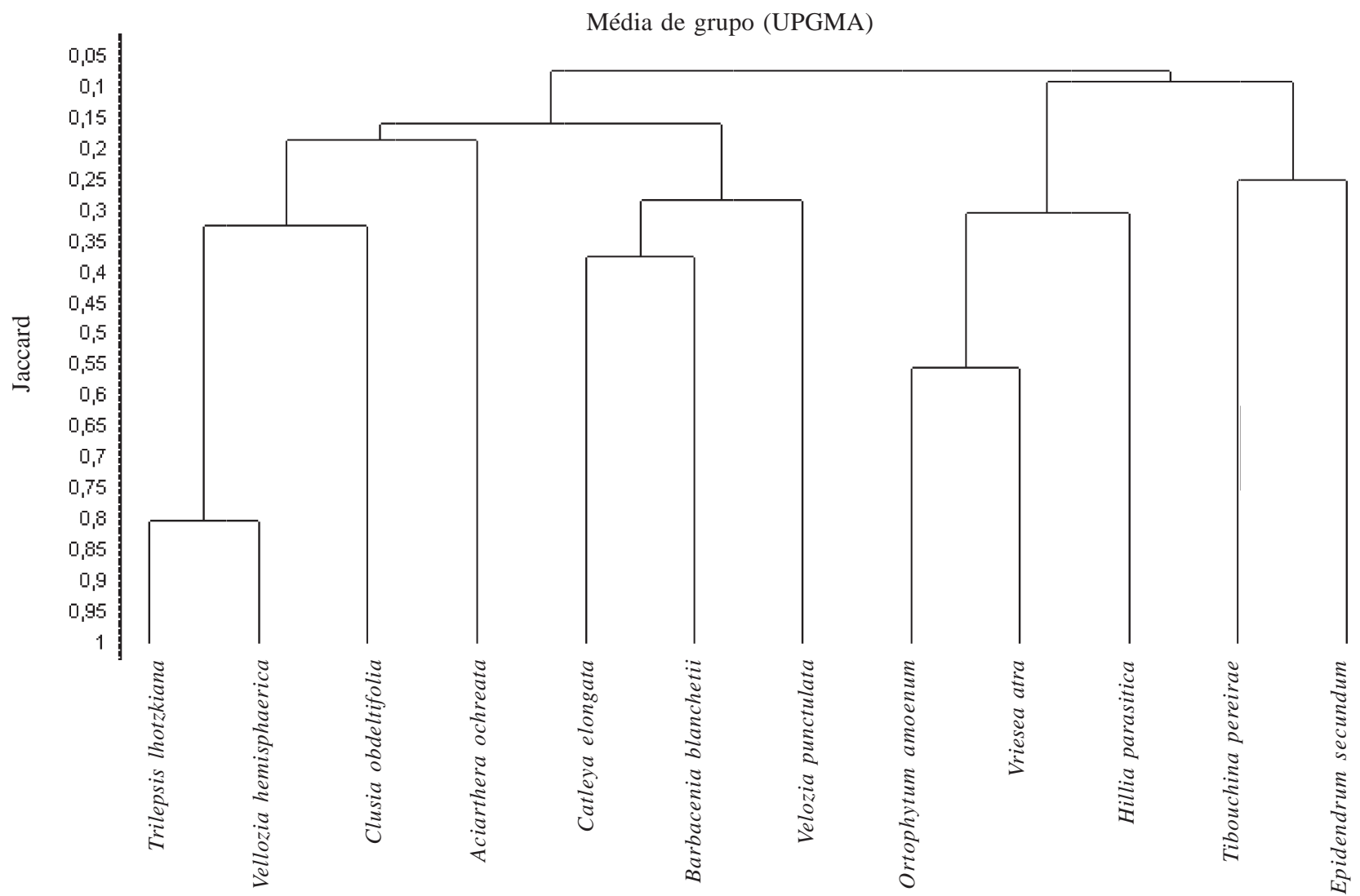

Figura 4. Dendrograma com as espécies ocorrentes em cinco ou mais ilhas de vegetação nos dois platôs do Morro do Pai Inácio, utilizando-se similaridade de Jaccard e UPGMA. Chapada Diamantina, Bahia, Brasil.

O valor do índice de Shannon calculado para ambos os platôs foi maior do que o calculado isoladamente para cada platô, demonstrando aumento da heterogeneidade no conjunto de ilhas dos dois platôs. Os valores do índice de Shannon estão dentro da variação encontrada em afloramentos rochosos do Rio de Janeiro (Meirelles et al. 1999), enquanto os valores da equitabilidade são menores no Morro do Pai Inácio, onde poucas espécies dominam. É importante mencionar que o estudo no Rio de Janeiro abrangeu um número maior de elevações isoladas entre si e que apesar dos dois platôs estudados no Morro do Pai Inácio situarem-se num mesmo morro, 41 das 63 espécies ocorreram em apenas um dos platôs, o que talvez seja devido às diferenças ambientais entre os platôs (Conceição \& Giulietti 2002), apesar da vegetação estudada restringir-se a um habitat típico de áreas rochosas com elevada superfície exposta. Outros fatores que podem ter influenciado no número elevado de espécies exclusivas a um platô incluem o acaso, o processo de colonização inicial e as perturbações (Peet 1992). Distinções em ilhas de vegetação de dois platôs em afloramentos rochosos contíguos também foram verificadas em Itatiaia, no Rio de Janeiro, onde houve segregação espacial de espécies relacionada à espécie dominante e à topografia (Medina et al. 2006).

Espécies camefíticas e hemicriptofíticas perfizeram a maior parte da cobertura das ilhas de vegetação de ambos os platôs do Morro do Pai Inácio, enfatizando a importância dessas duas formas de vida para a fisionomia das ilhas de vegetação no Morro do Pai Inácio, assim como encontrado em afloramentos rochosos no domínio da Mata Atlântica (Porembski et al. 1998), apesar de outros estudos de ilhas de vegetação no Rio de Janeiro e São Paulo demonstrarem maior proporção de espécies hemicriptofíticas (S.T. Meirelles, dados não publicados; Meirelles et al. 1999; Ribeiro \& Medina 2002). Em outros quatro afloramentos rochosos na Chapada Diamantina, a maioria das espécies foi fanerofítica, hemicriptofítica ou camefítica, sendo que as espécies camefíticas e fanerofíticas apresentaram as maiores áreas de cobertura (A.A. Conceição, dados não 

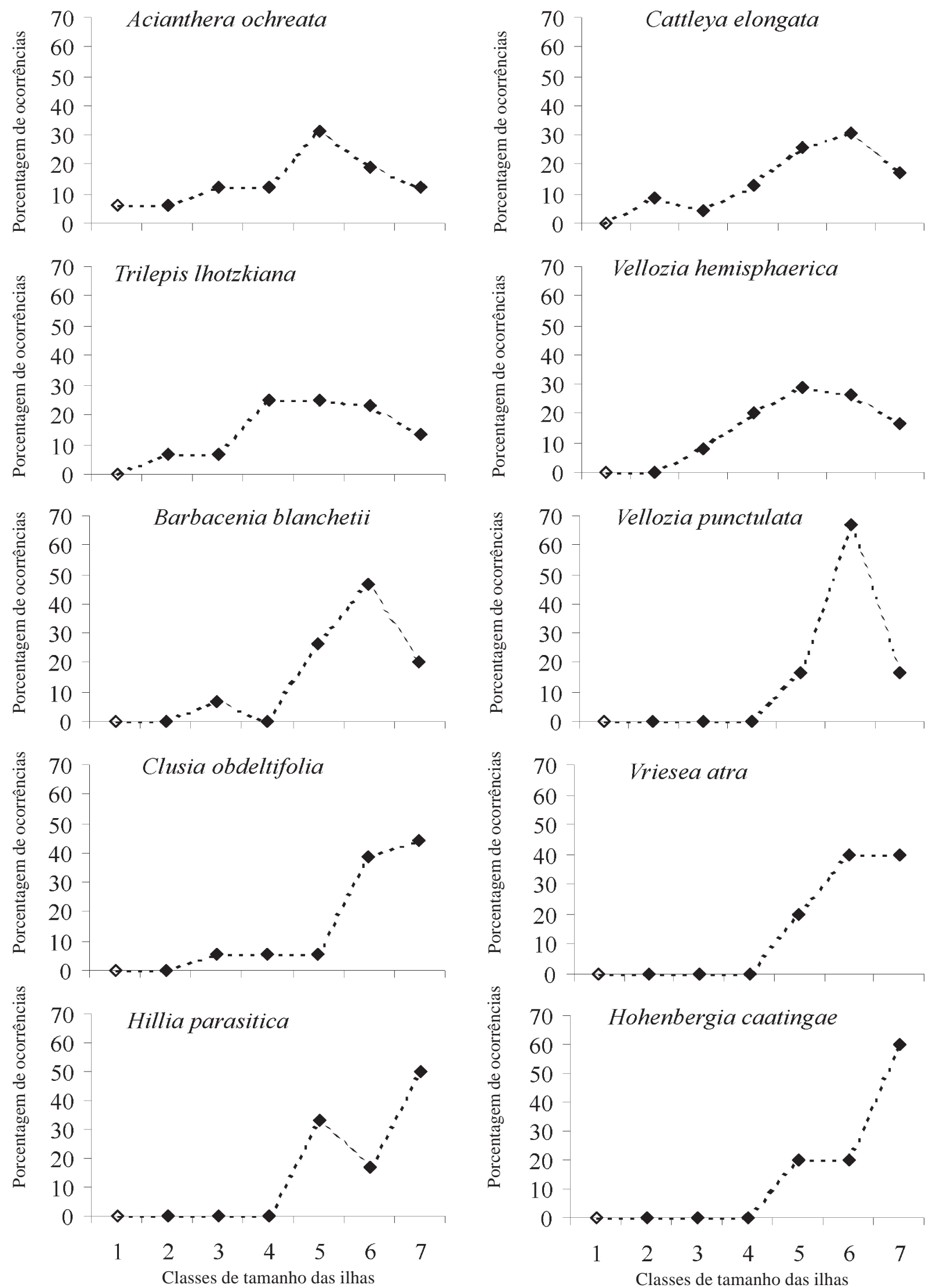

Figura 5. Porcentagens de ocorrências das dez espécies com maior dominância por classes de áreas insulares no Morro do Pai Inácio, Chapada Diamantina, Bahia, Brasil. 
publicados). Na Serra do Brigadeiro (Caiafa \& Silva 2005), das 56 espécies ocorrentes na sinúsia dos afloramentos rochosos, $70 \%$ são hemicriptofíticas ou camefíticas, confirmando a grande importância de ambas as formas de vida no substrato rochoso.

Em afloramento rochoso em São Paulo, os órgãos de resistência das espécies criptofíticas apresentaram-se como estruturas que muitas vezes ocupavam grande parte do volume do substrato (Meirelles 1996), permitindo que os meristemas estivessem efetivamente abrigados, mesmo quando não houvesse substrato profundo. Desta forma, essas espécies seriam capazes de rebrotar com mais eficácia sob secas e queimadas consecutivas, o que poderia ter favorecido a persistência de espécies criptofíticas no Platô Dois, onde a suscetibilidade ao fogo é maior, devido à vegetação mais contínua e próxima do cerrado (Conceição \& Giulietti 2002). Arbustos e arvoretas de H. parasitica, C. obdeltifolia e Tibouchina pereirae representaram as maiores proporções de fanerófita, sendo responsáveis por grandes áreas sombreadas nas ilhas de vegetação nos platôs, principalmente nas ilhas de vegetação maiores (Fig. 5), onde essas duas últimas espécies foram as únicas a incluir indivíduos ultrapassando $2 \mathrm{~m}$ de altura (microfanerófita). As plântulas de $C$. obdeltifolia e $V$. atra, praticamente ausentes em ilhas pequenas e mais freqüentes nas unidades de maior área, estabelecem-se geralmente em locais sombreados, mais comuns nas ilhas maiores.

A cobertura das espécies camefíticas representa $75 \%$ da área de cobertura de todas as espécies nas ilhas de vegetação estudadas no Morro do Pai Inácio, ressaltando ainda mais a importância dessa forma de vida nas ilhas de vegetação. Espécies de Velloziaceae, Cyperaceae e Orchidaceae foram as principais responsáveis pelo predomínio de caméfita, sendo que a Orchidaceae $C$. elongata, a exemplo de outras espécies de Orchidaceae que crescem sobre a rocha sem solo (Bennett 1991), destacou-se pela presença de raízes estendendo-se pela superfície rochosa por até metros de distância da planta. Quando presente em ilhas maiores, essa espécie ocorria principalmente nos limites da ilha com a rocha, ressaltando sua ligação com a superfície rochosa e exposição à radiação solar. Escapos da inflorescência de C. elongata caídos enraizaram-se isoladamente na rocha, caracterizando a propagação vegetativa mais comumente observada nos afloramentos. Esse fato sugere que a elevada concentração de $C$. elongata em alguns locais dos afloramentos possa ter ocorrido a partir da reprodução vegetativa de um ou poucos indivíduos. A elevada cobertura de $V$. hemisphaerica (Velloziaceae) e a elevada frequiência de T. lhotzkiana (Cyperaceae) evidenciam a afinidade dessas espécies pelo substrato rochoso, o que provavelmente deve estar associado à tolerância à dessecação dessas espécies (A.A. Conceição, dados não publicados), a exemplo de outras espécies dessas famílias (Owoseye \& Sanford 1972; Gaff 1977; Meguro et al. 1977; Meirelles et al. 1997), possibilitando a exploração desse ambiente sujeito a períodos de seca extrema.

Todas as espécies que compuseram ilhas com uma única espécie são camefíticas, evidenciando seu papel fundamental na sucessão primária, assim como relatado para outros afloramentos de quartzito-arenito em Minas Gerais (Alves \& Kolbek 2000). As ocorrências das Orchidaceae ( $C$. elongata e A. ochreata) e Cyperaceae ( $T$. lhotzkiana) nas ilhas menores confirmam a relevância dessas famílias nos processos iniciais de ocupação da rocha (Hambler 1964; Meirelles et al. 1997; Alves \& Kolbek 2000). As Velloziaceae também são importantes, porém em ilhas um pouco maiores, decrescendo de importância na classe com as maiores ilhas (Fig. 5). É importante notar que devido ao maior número de ilhas na classe cinco (Fig. 2), existe tendência geral em um aumento na proporção de ocorrência nessa classe. Em ilhas de vegetação estudadas na Venezuela (Michelangeli 2000), outras monocotiledôneas também estiveram presentes em todo o gradiente de área insular. A ocorrência das espécies pioneiras em ilhas maiores provavelmente se concentra nas bordas da ilha, onde o ambiente é mais extremo (McCormick et al. 1974). Devido à escassez de solo, a maior parte do substrato nas ilhas se constitui de raízes emaranhadas sobre a rocha (Conceição \& Pirani 2005). As raízes somadas aos restos de vegetais e porções aéreas das plantas promovem retenção de material particulado de modo a influenciar no desenvolvimento da estrutura de suporte (Weaver \& Clements 1938). As estruturas formadas pela adição das bainhas foliares características das espécies de Velloziaceae e Cyperaceae sugerem que essas tenham grande importância para o estabelecimento de espécies nos afloramentos rochosos (Hambler 1964), constituindo grande parte do substrato nas ilhas.

Nas ilhas maiores, a inclusão de arbustos e arvoretas promove diminuição da insolação no estrato inferior das bordas das ilhas, o que poderia favorecer a substituição gradual dessas espécies por outras que não suportam insolação direta durante o dia todo, podendo ser mais exigentes quanto aos recursos advindos do substrato. Segundo modelo de sucessão 
proposto para os afloramentos de quartzito-arenito da Chapada Diamantina (A.A. Conceição, dados não publicados), as ilhas tendem a crescer, juntando-se gradualmente às ilhas contíguas, que posteriormente se conectam com a vegetação adjacente mais contínua e dominada por gramíneas e arbustos. Esse processo estaria ocorrendo concomitantemente em vários estágios em diversas áreas de afloramentos rochosos, sendo que devido às porções de superfície rochosa sem combustível, o fogo não atinge tanto as ilhas de vegetação como os locais com vegetação herbáceoarbustiva contínua que entremeia os afloramentos, ressaltando a importância das secas na dinâmica das ilhas.

Dentre as espécies representadas no dendrograma (Fig. 4), T. pereirae e E. secundum são as únicas que também são características de outros habitats além das ilhas, como frestas e solos arenosos extensos (Conceição \& Giulietti 2002; Conceição \& Pirani 2005), compondo um grupo mais generalista e não tão característico das ilhas de vegetação como as espécies dos demais grupos, formados por espécies típicas do substrato rochoso no Morro do Pai Inácio. As espécies de Orchidaceae, Velloziaceae e T. lhotzkiana (Cyperaceae) formam grupos importantes para sucessão primária. As mesmas famílias foram mencionadas no processo de sucessão primária em afloramentos de quartzito-arenito de Minas Gerais, principalmente Orchidaceae representada pelo gênero Acianthera (Alves \& Kolbek 2000). Ilhas combinando espécies de Velloziaceae e Cyperaceae também foram encontradas em afloramentos da África (Owoseye \& Sanford 1972; Barthlott et al. 1993), além de outras regiões do Brasil (Meirelles et al. 1999). As espécies de Velloziaceae B. blanchetii e $V$. punctulata foram amostradas exclusivamente no Platô Dois, indicando maior ligação deste grupo neste platô, apesar de C. elongata estar presente em ambos os platôs. O grupo formado por espécies de Bromeliaceae e Rubiaceae provavelmente está relacionado às encostas, corroborando com o habitat característico de O. amoenum, freqüentemente encontrado em locais mais sombreados e inclinados, nas bordas dos afloramentos, onde indivíduos pequenos de $V$. atra também foram freqüentes. A Rubiaceae $H$. parasitica foi amostrada exclusivamente no Platô Cruz, onde as encostas são mais pronunciadas.

Portanto, a estrutura da vegetação em ilhas de vegetação nos afloramentos do Morro do Pai Inácio é conferida por um número reduzido de espécies que pertencem a gêneros e famílias comuns a outros afloramentos. A maioria desses táxons é formada por representantes das Liliopsida e a combinação entre Velloziaceae e Cyperaceae persiste como associação típica do substrato rochoso, interagindo nos processos iniciais de sucessão, juntamente com outras espécies de Orchidaceae. Nas ilhas maiores, arbustos e arvoretas de Guttiferae, Melastomataceae e Rubiaceae sombreiam o solo, alterando gradualmente as condições ambientais das ilhas. Diferenças na composição e abundância de espécies entre os platôs sugerem a existência de diferenças ambientais e isolamentos, interferindo na distribuição espacial das espécies nas ilhas de vegetação em cada platô, apesar da fisionomia permanecer relativamente semelhante.

\section{Agradecimentos}

À CAPES, pela bolsa de mestrado concedida ao primeiro autor; ao CNPq pelo auxílio financeiro que viabilizou o trabalho de campo; ao IBAMA, pela concessão de permissão de coleta no Parque Nacional da Chapada Diamantina; ao Prof. Dr. José Rubens Pirani, curador do herbário SPF; ao Roy Funch e C.van den Berg pelo abstract; ao Alexandre Grillo pela ajuda no campo; aos revisores anônimos e Profs. Drs. Alexandre Adalardo, Fabio de Barros, Marico Meguro e Vânia Pivello pela leitura crítica e sugestões. Aos botânicos especialistas A. Brito (Orchidaceae), A. Rapini (Apocynaceae), A. Zanin (Poaceae), A.C. Araújo (Cyperaceae), C.van den Berg (Orchidaceae), D. Zappi (Cactaceae), E. Jacques (Begoniaceae), F. Costa (Eriocaulaceae), F. Vitta (Cyperaceae), G. Pedralli (Dioscoreaceae), H. Longhi-Wagner (Poaceae), J. Baumgratz (Melastomataceae), J. Coffani-Nunes (Bromeliaceae), J. Prado (Pteridophyta), J. Semir (Compositae), J. Wurdack (Melastomataceae), L. Lohmann (Bignoniaceae), L.P. Queiroz (Mimosaceae), M. Wanderley (Bromeliaceae), D. Hind (Compositae), P. Labiak (Pteridophyta), R. Forzza (Bromeliaceae), R. MelloSilva (Velloziaceae), T.Silva (Verbenaceae) e W.W. Thomas (Cyperaceae).

\section{Referências bibliográficas}

Alves, R.J.V. \& Kolbek, J. 1993. Penumbral rock communities in campo rupestre sites in Brazil. Journal of Vegetation Science 4: 357-366.

Alves, R.J.V. \& Kolbek, J. 2000. Primary succession on quartzite cliffs in Minas Gerais, Brazil. Biologia Bratislava 55(1): 69-83. 
Barthlott, W.; Gröger, A. \& Porembski, S. 1993. Some remarks on the vegetation of tropical inselbergs: diversity and ecological differentiation. Biogeographica 69: 17-36.

Bennett, B.C. 1991. Comparative biology of neotropical epiphytic and saxicolous Tillandsia species: population structure. Journal of Ecology 7: 361-371.

Brummitt, R.K. \& Powell, C.E. 1992. Authors of plant names. Kew, Royal Botanic Gardens.

Burbanck, M.P. \& Platt, R.B. 1964. Granite outcrop comunities of the Piedmont Plateau in Georgia. Ecology 45: 292-306.

Burrows, C.J. 1990. Processes of vegetation change. London, Urwin Hyman.

Caiafa, A.N. \& Silva, A.F. 2005. Composição florística e espectro biológico de um campo de altitude no Parque Estadual da Serra do Brigadeiro, Minas Gerais - Brasil. Rodriguésia 56(87): 163-173.

Carauta, J.P.P. \& Oliveira, R.R. 1984. Plantas vasculares dos morros da Urca, Pão de Açúcar e Cara de Cão. Rodriguésia 36: 13-24.

Conceição, A.A. 2000. Alerta para a conservação da biota na Chapada Diamantina. Revista Ciência Hoje 27(159): 54-56.

Conceição, A.A. \& Giulietti, A.M. 2002. Composição florística e aspectos estruturais de campo rupestre em dois platôs do Morro do Pai Inácio, Chapada Diamantina, Bahia, Brasil. Hoehnea 29(1): 37-48.

Conceição, A.A. \& Pirani, J.R. 2005. Delimitação de habitats em campos rupestres na Chapada Diamantina, Bahia: substratos, composição florística e aspectos estruturais. Boletim de Botânica da Universidade de São Paulo 23(1): 85-111.

Conceição, A.A.; Rapini, A.; Pirani, J.R.; Giulietti, A.M; Harley, R.M.; Silva, T.R.; Santos, A.K.; Correia, C.; Andrade, I.M; Costa, J.A.S.; Souza, L.R.S.; Andrade, M.J.G; Funch, R.R.; Freitas, T.A.; Freitas, A.M.M. \& Oliveira, A.A. 2005. Campos Rupestres. Pp. 153-180. In: F.A. Juncá; L. Funch \& W. Rocha (eds.). Biodiversidade e Conservação da Chapada Diamantina. Brasília, Ministério do Meio Ambiente.

Cronquist, A. 1981. An integrated system of classification of flowering plants. New York, Columbia University Press.

França, F.; Melo, E. \& Santos, C.C. 1997. Flora de inselbergs da região de Milagres, Bahia: caracterização da vegetação e lista de espécies de dois inselbergs, Brasil. Sitientibus 17: 163-184.

Gaff, D.F. 1977. Desiccation tolerant vascular plants of Southern Africa. Oecologia 31: 95-109.

Giulietti, A.M. \& Pirani, J.R. 1988. Paterns of geographic distribution of some plant species from the Espinhaço Range, Minas Gerais and Bahia, Brasil. Pp. 39-69. In: P.E. Vanzolini, \& W.R. Heyer (eds.). Proceedings of a workshop on neotropical distribution patterns. Rio de Janeiro, Academia Brasileira de Ciências.

Giulietti, A.M.; Pirani, J.R. \& Harley, R.M. 1997. Espinhaço Range Region, Eastern Brazil. Pp. 397-404. In: S.D. Davis, V.H. Heywood, O. Herrera-Macbryde, J. Villa-Lobos \& A.C. Hamilton (eds.). Centres of plant diversity. A guide and strategy for their conservation. v.3. The Americas. Cambridge, IUCN Publication Unity.
Hambler, D.J. 1964. The vegetation of granitic outcrops in western Nigeria. Journal of Ecology 52: 573-594.

Harley, R.M. 1995. Introduction. Pp. 1-42. In: B.L. Stannard (ed.). Flora of the Pico das Almas, Chapada Diamantina, Brazil. Kew, Royal Botanic Gardens.

Ibisch, P.L.; Rauer, G.; Rudolph, D. \& Barthlott, W. 1995. Floristic, biogeographical, and vegetational aspects of Pre-Cambrian rock outcrops (inselbergs) in eastern Bolivia. Flora 190: 299-314.

Krebs, C.J. 1989. Ecological methodology. New York, Harper \& Row.

MacArthur, R.H. \& Wilson, E.O. 1967. The theory of island biogeography. New Jersey, Princeton University Press.

Magurran, A.E. 1988. Ecological diversity and its measurement. New Jersey, Princeton University Press.

McCormick, J.F; Ariel, E.L. \& Sharitz, R.R. 1974. Experimental analysis of ecosystems. Pp. 151-179. In: B.R. Strain \& W.D. Billings (eds.). Vegetation and environment. Netherlands, The Hague.

Meirelles, S.T.; Mattos, E.A. \& Silva, A.C. 1997. Potential desiccation tolerant vascular plants from Southeastern Brazil. Polish Journal of Environmental Studies 6(4): 17-21.

Meirelles, S.T.; Pivello, V.R. \& Joly, C.A. 1999. The vegetation of granite rock outcrops in Rio de Janeiro, Brazil, and the need for its protection. Environmental Conservation 26(1): 10-20.

Meguro, M.; Joly, C.A. \& Bittencourt, M.M. 1977. Stress hídrico e alguns aspectos do comportamento fisiológico em Xerophyta plicata Spreng. - Velloziaceae. Boletim de Botânica da Universidade de São Paulo 5: 27-42.

Medina, B.M.O.; Ribeiro, K.T. \& Scarano, F.R. 2006. Plantplant and plant-topography interactions on a rock outcrop at high altitude in southeastern Brazil. Biotropica 38(1): 27-34.

Michelangeli, F.A. 2000. Species composition and speciesarea relationships in vegetation isolates on summit of a sandstone mountain in southern Venezuela. Journal of Tropical Ecology 16: 69-82.

Misi, A. \& Silva, M.G. 1996. Chapada Diamantina Oriental - Bahia: geologia e depósitos minerais. Salvador, Superintendência de Geologia e Recursos Minerais (Série roteiros geológicos).

Mueller-Dombois, D. \& Ellenberg, H. 1974. Aims and methods of vegetation ecology. New York, John Wiley \& Sons.

Nimer, N. 1989. Climatologia do Brasil. Rio de Janeiro, IBGE.

Oliveira, R.F.; Coimbra Filho, A.F. \& Silva, Z.L. 1975. Sobre litosere: algumas espécies para revestimento de encostas rochosas. Brasil Florestal 6(24): 3-18.

Owoseye, J.A. \& Sanford, W.W. 1972. An ecological study of Vellozia schnitzleinia, a drougth-enduring plant of northern Nigeria. Journal of Ecology 60: 807-817.

Peet, K.R. 1992. Community structure and ecosystem function. Pp.103-151. In: D.C. Glenn-Lewin; R.K. Peet \& T.T. Veblen (eds.). Plant Succession: theory and prediction. Cambridge, Chapman \& Hall.

Pielou, E.C. 1984. The interpretation of ecological data. New York, John Wiley \& Sons. 
Porembski, S.; Barthlott, W.; Dörrstock, S. \& Biedinger, N. 1994. Vegetation of rock outcrops in Guinea: granite inselbergs, sandstone table mountains and ferricretes remarks on species numbers and endemism. Flora 189(4): 315-326.

Porembski, S.; Brown, G. \& Barthlott, W. 1995. An inverted latitudinal gradient of plant diversity in shallow depressions on ivorian inselbergs. Vegetatio 117: 151-163.

Porembski, S.; Martinelli, G.; Ohlemüller, R. \& Barthlott, W. 1998. Diversity and ecology of saxicolous vegetation mats on inselbergs in the Brazilian Atlantic rainforest. Diversity and Distributions 4: 107-119.

Prance, G.T. 1994. A comparison of the efficacy of higher taxa and species number in assessment of biodiversity in the neotropics. Philosophical Transactions of the Royal Society of London. Series B, Biological Sciences 345: 89-99.

Ribeiro, K.T. \& Medina, B.M.O. 2002. Estrutura, dinâmica e biogeografia das ilhas de vegetação sobre rocha do Planalto do Itatiaia, RJ. Boletim do Parque Nacional do Itatiaia 10: 11-82.

Safford, H.D. \& Martinelli, G. 2000. Southeast Brazil. Pp. 339-389. In: S. Porembski \& W. Barthlott (eds.). Inselbergs. Heidelberg, Ecological Studies, v.146. Springer-Verlag.
Sarthou, C. \& Villiers, J. 1998. Epilithic plant communities on inselbergs in French Guiana. Journal of Vegetation Science 9: 847-860.

Seine, R.; Porembski, S. \& Becker, U. 2000. Phytogeography. Pp. 435-449. In: S. Porembski \& W. Barthlott (eds.). Inselbergs. Heidelberg, Ecological Studies, v.146. Springer-Verlag.

Shepherd, G.J. 2006. FITOPAC 1.6. Campinas, Universidade Estadual de Campinas.

Shure, D.J. \& Ragsdale, L. 1977. Patterns of primary succession on granite outcrop surfaces. Ecology 58: 993-1006.

Torquato, J.R. \& Fogaça, A.C.C. 1981. Correlação entre o Supergrupo Espinhaço no Brasil, o Grupo Chela em Angola e as Formações Nasib e Khoabendus da Namíbia. Pp. 87-99. In: Anais do simpósio sobre o Craton do São Francisco e suas faixas marginais. Salvador, Sociedade Brasileira de Geologia - Núcleo da Bahia, coordenação da produção mineral.

Weaver, J.E. \& Clements, F.E. 1938. Plant Ecology. New York, McGraw-Hill.

Westhoff, V. \& Maarel, E. van der 1978. The Braun-Branquet Approach. Pp. 287-399. In: R.H. Whittaker (ed.). Classification of plant communities. Boston, Dr W. Junk.

Wiser, S.K.; Peet, R.K. \& White, P.S. 1996. High-elevation rock outcrop vegetation of the Southern Appalachian Mountains. Journal of Vegetation Science 7: 703-722. 